\title{
DISCUSSÕES SOBRE AS IMPLICAÇÕES DO ENSINO DE NOVE ANOS: INICIAÇÃO AO ENSINO DA MATEMÁTICA
}

\author{
Klinger Teodoro Ciríaco
}

Doutorando em Educação (Educação Matemática) pela FCT/UNESP-Presidente Prudente-SP. E-mail: ciriaco.unesp@hotmail.com

\begin{abstract}
RESUMO
Este artigo relata resultados preliminares de uma Dissertação de Mestrado vinculada ao Programa de PósGraduação em Educação da Universidade Estadual Paulista "Júlio de Mesquita Filho" e tem por objetivo geral uma análise qualitativa sobre as práticas de ensino de Matemática desenvolvidas por um grupo de professoras de Educação Infantil e Ensino Fundamental da rede municipal de ensino de Presidente Prudente (SP). Para tal, foram selecionadas duas escolas de Educação Infantil e Ensino Fundamental (EMEIFs) do município. Esta investigação tem um caráter qualitativo, o que permite ao pesquisador um contato direto com o ambiente investigado na tentativa de que por meio das análises feitas se possa compreender como as políticas de ampliação do Ensino Fundamental refletem na prática pedagógica dos professores que ensinam Matemática na infância. Neste estudo, busca-se compreender como o trabalho com a disciplina esta sendo feito após implementação do ensino de nove anos no período de transição da pré-escola para $01^{\circ}$ ano. Entende-se que a iniciação à Matemática deve ser feita por meio da exploração do pensamento matemático na primeira infância e que cabe ao professor propiciar um ambiente para que a aprendizagem ocorra de maneira pacífica para que não ocorra uma escolarização precoce da criança, o que pode comprometer as características do desenvolvimento infantil. Assim, compreender as possíveis implicações da inclusão de mais um ano no Ensino Fundamental no que se refere ao currículo da Matemática escolar pretende ser as contribuições deste estudo com o intuito de pautar uma discussão sobre como a Matemática têm sido abordada no contexto da ampliação do Ensino Fundamental.

Palavras-chave: Ensino Fundamental. Práticas de Professores. Aprendizagem Matemática.
\end{abstract}

\section{DISCUSSIONS ON THE IMPLICATIONS OF EDUCATION OF NINE YEARS: STARTED THE TEACHING OF MATHEMATICS}

\begin{abstract}
This paper reports preliminary results of a Dissertation linked to the Graduate Program in Education at Universidade Estadual Paulista "Julio de Mesquita Filho" and aims at a general qualitative analysis on the practices of teaching mathematics developed by teachers municipal schools in Presidente Prudente (SP). To this end, we selected two schools from kindergarten and elementary school (EMEIFs) in the city. This research has a qualitative character, which allows the researcher to have direct contact with the environment investigated in the attempt that through the analysis made in understanding how the policies of expansion of basic education reflect the pedagogical practice of teachers who teach mathematics in childhood. In this study, we sought to understand how to work with discipline is being done after the implementation of education for nine years during the transition from preschool to first grade. We believe that the initiation of Mathematics should be made through the exploitation of mathematical thinking in early childhood and that the teacher provide an environment for learning to occur in a peaceful manner so that does not a child's early education, which may compromise characteristics of child development. Thus, understanding the possible implications of adding one more year in elementary school when it comes to the school mathematics curriculum is intended to be the contributions of this study with the aim of basing a discussion of how mathematics has been addressed in the expansion of education fundamental.
\end{abstract}

Keywords: Teaching of Nine Years. Practice Teachers. Learning Mathematics. 


\section{INTRODUÇÃO}

Neste artigo, o ponto de discussão referese a considerações iniciais sobre uma pesquisa, de cunho qualitativo, em desenvolvimento junto ao Programa de Pós-Graduação Mestrado em Educação da FCT/UNESP.

Para tal, esclareço ainda, que os escritos que aqui se apresentam compõem parte do referencial teórico que será discutido com maior abrangência no decorrer da produção da Dissertação de Mestrado.

Neste sentido, inicio o texto lembrando que até recentemente, o período circunscrito para a idade média de escolarização básica no Ensino Fundamental era o de crianças em idade de sete anos, porém com a Lei Federal $n^{\circ} 11.114^{1}$, de 16 de maio de 2005, que obriga a matrícula das crianças de 6 (seis) anos alterando os art. 6.․, 30, 32 e 87 da Lei Federal n. ${ }^{\circ}$ 9394, de 20 /12 /96, dispondo sobre a duração mínima de 9 (nove) anos para o Ensino Fundamental reafirmando a matrícula obrigatória a partir dos 6 (seis) anos de idade para todo o sistema de ensino brasileiro.

A relevância de se desenvolver estudos e reflexões sobre a implementação de tal medida encontra respaldo pelo fato de que conforme aponta Maria Malta Campos (2007) os estudos realizados a partir da ampliação do Ensino Fundamental têm revelado "[...] preocupação com a escolarização considerada precoce das crianças de seis anos - e até daquelas de cinco anos - [...]" (p. 20), ao que indago: de que forma tal mudança tem contribuído para 0 desenvolvimento de nossas crianças? Em particular, em Matemática, quais as orientações, observações e práticas estão se fazendo no âmbito da escola?

\footnotetext{
${ }^{1}$ Essa foi a primeira lei que aborda aspectos sobre a ampliação do ensino fundamental, apesar de ser a Lei 11. 274 que estabelece a obrigação da matrícula da criança de seis anos, abordaremos toda a legislação que envolve esta temática no desenvolvimento da pesquisa.
}

Estas inquietações decorrem primeiramente porque,

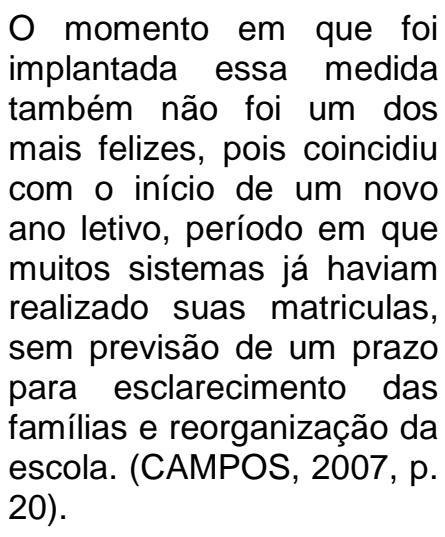

No campo da Educação Infantil, são muitas as implicações que as pesquisas da área vêm apontando, em especial considera pertinente destacar a preocupação de comprometermos, com uma escolarização precoce, o desenvolvimento infantil da criança.

O exame das questões analisadas, durante o desenvolvimento da pesquisa, passa necessariamente por reflexões sobre essa mudança curricular, ou seja, da inclusão de mais um ano no Ensino Fundamental. Para tanto, será analisada a proposta de implementação desta medida no município de Presidente Prudente (SP), para posterior compreensão de como os professores estão desenvolvendo, em sua prática pedagógica, o ensino de Matemática.

Cabe acrescentar, que por este trabalho se tratar da iniciação à Matemática na infância, a discussão se pautará em questões que compreendem 0 período de transição da Educação Infantil (pré-escola) para o Ensino Fundamental (primeiro ano).

\section{Sinais do Objeto de Estudo: a escolha por uma metodologia adequada}

Como proposta metodológica foi estabelecida para a realização deste trabalho de pesquisa a abordagem qualitativa, devido a sua abrangência e pela vantagem em facilitar ao 
pesquisador o contato direto com o ambiente e com a situação que se está investigando.

Esta abordagem permite compreender 0 contexto no seu cenário natural e preservar a complexidade do comportamento humano, observar fenômenos em um pequeno grupo, interpretar comportamentos e técnicas de observação da realidade, através de participação em ações do grupo, por meio de entrevistas e conversas para descobrir as interpretações sobre as situações observadas, permitindo comparar e interpretar as respostas encontradas em situações adversas.

O objetivo geral do estudo é: investigar, no processo de trabalho pedagógico de professores polivalentes, como se realiza a transição dos conteúdos matemáticos da Educação Infantil para o Ensino Fundamental de nove anos, desvelando os condicionantes e as racionalidades que emergem de suas práticas pedagógicas, tendo em vista as relações com a formação em Pedagogia.

Assim, durante 0 processo da investigação,

Caminha-se por vários dias entre árvores e pedras. Raramente o olhar se fixa numa coisa, e, quando isso acontece, ela é reconhecida pelo símbolo de alguma outra coisa: a pegada na areia indica a passagem de um tigre; o pântano anuncia uma veia de água; a flor do hibisco, o fim do inverno. O resto é mudo e intercambiável árvores e pedras são apenas aquilo que são. (CALVINO, 1990, p. 17).

Me valido do trecho de Calvino (1990) por que para atingir os objetivos previstos no percurso metodológico da pesquisa, serão utilizados diferentes instrumentos para a coleta de dados, assim o "caminhar por dias entre árvores e pedras" seria como se imaginássemos o tempo em que o pesquisador destina para a coleta de dados, no caso deste estudo um ano (agosto de 2010 à julho de 2011).

Nas observações em sala de aula, ocorridas entre o ano letivo de 2010 em duas salas de pré-escola e em 2011 em turmas de primeiro ano, "raramente o olhar se fixa numa coisa", seriam os professores, as crianças, as atividades propostas, as situações didáticas que envolvam aspectos da Educação Matemática? Sem dúvidas o campo de configuração de uma pesquisa envolve muitas "coisas" e se os objetivos não estiverem claros, coesos e sustentados teoricamente, o pesquisador pode se confundir e não reconhecer o "símbolo" ou a pegada do "tigre na areia", aquela que conduz, orienta e sustenta a pesquisa.

Neste contexto, parto da premissa de que as atividades matemáticas desenvolvidas pelos professores em sala de aula não podem prescindir da Matriz Curricular para a antiga $1^{\underline{a}}$ série do Ensino Fundamental de oito anos, pois, conforme afirma as publicações do Ministério da Educação (MEC), é hora de (re) pensar as práticas pedagógicas desenvolvidas no seio da escola, portanto compreendo que um estudo entre as propostas curriculares para o ensino de Matemática pela via da prática do professor parece ser uma rica e promissora oportunidade a ser explorada neste momento de mudança curricular que estamos a vivenciar na realidade educacional brasileira.

Assim, cabe perguntar: Como os professores aderiram a nova proposta curricular? Como estão iniciam o trabalho com as crianças de cinco e seis anos que na legislação anterior estariam freqüentando os espaços de Educação para a Infância? Se houve, então como aconteceu à adesão da nova proposta curricular? Que adaptações às escolas fizeram para receber as crianças? 
Para responder tais questões, é preciso esclarecer que no campo da Educação Matemática existem algumas tendências ou paradigmas temáticos e metodológicos da pesquisa. Segundo Kilpatrick (1994 apud FIORENTINI; LORENZATO, 2009) são:

- Processo ensino-aprendizagem da matemática;

- Mudanças curriculares;

- Utilização de Tecnologias de Informação e Comunicação (TICs) no ensinoaprendizagem da matemática;

- Prática docente, crenças, concepções e saberes práticos;

- Conhecimentos formação/desenvolvimento profissional do professor;

- Práticas de avaliação;

- Contexto sociocultural e político do ensino-aprendizagem da matemática.

Nesta perspectiva, embora o objeto de estudo da Educação Matemática ainda se encontre em processo de construção, poderíamos, de modo geral, dizer que ele envolve as múltiplas relações e determinações entre ensino, aprendizagem e conhecimento matemático em um contexto sociocultural específico (FIORENTINI; LORENZATO, 2009).

Segundo Fiorentini e Lorenzato (2009), produzir conhecimento na área da Educação Matemática não significa que seja preciso abordar todas as tendências apontadas por Kilpatrick (1994), ou seja, uma determinada investigação pode priorizar um determinado elemento ou ainda fazer uma relação entre eles.

Seguindo esta linha de raciocínio, a pesquisa intitulada: Ensino Fundamental de Nove Anos: entre as políticas oficiais e a prática de professores que ensinam Matemática em EMEIFs de Presidente Prudente $(S P)^{2}$ segue mais de uma tendência, pois, para realização deste estudo o pesquisador teve de se "apropriar" de aspectos de uma mudança curricular (ampliação do Ensino Fundamental); conhecimentos e formação matemática inicial obtidos na graduação em Pedagogia, bem como a prática docente e os processos de ensino adotados pelos sujeitos da pesquisa para iniciar 0 trabalho com a Matemática no contexto do Ensino Fundamental de nove anos.

\section{Ensino de Nove Anos: a quem se destina?}

A ampliação do Ensino Fundamental traz consigo inúmeras indagações que possibilitam levantar questões inerentes ao objeto de estudo aqui apresentado. Em particular, essa reflexão nos obriga pensar outros rumos no que se refere à prática pedagógica dos professores que ensinam Matemática nos primeiros anos de escolarização.

Neste caso, torna-se indispensável uma discussão abrangente sobre a ampliação do Ensino Fundamental, uma vez que essa mudança acarreta algumas implicações para o currículo da Matemática escolar. Esta lei é parte de uma política educacional que inclui a criança a partir de seis anos no Ensino Fundamental, alterando com isso a sua duração de oito para nove anos, e ainda expõe as crianças que anteriormente eram da Educação Infantil a uma escolarização precoce.

A relevância em analisar os aspectos que tal mudança possa trazer para a prática dos professores, encontra respaldo em pesquisas já realizadas sobre alfabetização em que os professores iniciam precocemente alguns conteúdos para as crianças 'pequenas' no Ensino Fundamental (MOYA, 2009; SILVA, 2009; ARAÚJO, 2008). Com base nessas conclusões,

\footnotetext{
${ }^{2}$ Vinculada ao Programa de Pós-Graduação da Faculdade de Ciências e Tecnologia FCT/UNESP.
} 
pretendo verificar se com Matemática acontece o mesmo, sendo preciso para tal observar as atividades propostas em sala de aula, a prática docente, bem como outros aspectos que possam compor o cenário da investigação.

Em nosso país inúmeras discussões vêm se fazendo nos meios acadêmicos no que se refere ao acréscimo de um ano escolar no Ensino Fundamental, no cenário destas investigações uma questão se faz presente: Desrespeito à infância ou garantia de permanência da criança na escola?

Essa questão vem movendo pesquisadores de várias regiões, em especial nos últimos dois anos, por vários motivos: diminuição do tempo destinado à Educação Infantil; obrigatoriedade de matrícula no Ensino Fundamental para as crianças consideradas ainda em idade pré-escolar, dúvidas de professores em exercício sobre qual a melhor forma de atuar, entre outros.

Assim no ano de 2006 ocorreu uma mudança no Ensino Fundamental que passou, a partir desta data, a 9 (nove) anos de obrigatórios, fato esse que implica a matrícula de todas as crianças a partir dos 6 (seis) anos de idade. Tais crianças, na modalidade de ensino anterior, ainda estariam freqüentando a Educação Infantil. Pautada no artigo 5ำ da Lei n. 11.274/2006, a ampliação do Ensino Fundamental para nove anos se fez com vistas à meta do Plano Nacional de Educação (PNE), instituído pela Lei n. 10.172, de 9 de Janeiro de 2001, que propõe a "ampliação para nove anos a duração do ensino fundamental obrigatório com início aos seis anos de idade, à medida que for sendo universalizado o atendimento na faixa etária de 7 a 14 anos" (BRASIL, 2001).

Para tanto o MEC instituiu que:

[...] o Ensino Fundamental de nove anos é um movimento mundial e, mesmo na América do Sul, são vários os países que o adotam, fato que chega até a colocar jovens brasileiros em uma situação delicada, uma vez que, para continuar seus estudos nesses países, é colocada a eles a contingência de compensar a defasagem constatada. 2004, p.13).

O Plano Nacional de Educação (PNE) afirma que a institucionalização da escolaridade de nove anos obrigatória tem em seu desenvolvimento duas vertentes: "oferecer maiores oportunidades de aprendizagem no período da escolarização obrigatória e assegurar que, ingressando mais cedo no sistema de ensino, as crianças prossigam nos estudos, alcançando maior nível de escolaridade". (BRASIL, 2004).

Essas afirmações parecem não reconhecer o espaço de atuação da Educação Infantil que já desenvolvia o processo de iniciação das crianças na escolarização, embora ainda não obrigatória em todo o país.

Analisando por este lado, a política de obrigatoriedade do ensino de nove anos tem bons motivos para assegurar e contribuir para o desenvolvimento integral dos alunos, mas o que se questiona é o seguinte: As escolas primárias estão preparadas para receberem essas pequenas crianças? $O$ ensino de forma sistemática terá um nível teórico-metodologico eficaz com um grupo de crianças 'prematuras' para esta escolaridade? E os professores, o que pensam a respeito? Como essa mudança terá impacto em sua prática pedagógica? Em específico, o que muda no currículo e nas aulas de Matemática? Como está sendo feita a iniciação à Matemática, a partir da mudança do Ensino Fundamental?

Neste cenário de indagações, cabe salientar que este trabalho de pesquisa se coloca no sentido de apresentar quais as concepções do 
ensino de Matemática dos professores que lecionam na pré-escola e no primeiro ano, e ainda como pensam a respeito das implicações curriculares com a nova proposta de Ensino Fundamental. De fato, a mudança tem contribuído ou dificultado o processo de ensino e aprendizagem em Matemática?

Com respeito a esta questão, o Plano Nacional de Educação (PNE) ressalta que a inclusão de mais um ano no Ensino Fundamental requer "planejamento e diretrizes norteadoras para o atendimento integral da criança em seu aspecto físico, psicológico, intelectual e social" além é claro da expansão desse atendimento e da garantia à qualidade do ensino (BRASIL, 2004).

Assim é necessário refletirmos sobre as conseqüências dessa implementação e ampliação do Ensino Fundamental para o currículo de Matemática na Pré-escola e no $1^{\circ}$ ano de escolarização. Entendemos que essa discussão propicia-nos melhores esclarecimentos sobre as vantagens e desvantagens de tal mudança.

\section{Por que mudar?}

Os documentos que regulamentam a lei justificam o motivo da mudança referindo-se a resultados de pesquisas recentes que apontam que já há uma significativa porcentagem ${ }^{3}$ de crianças presentes na Educação Infantil e nas salas de aulas de Alfabetização. Com base nisso se reforça a opção pela mudança de ampliar o Ensino Fundamental, uma vez que isso possibilita, segundo esses documentos, um maior número de crianças inseridas no sistema educacional brasileiro (BRASIL, 2004).

Os setores populares deverão ser os mais beneficiados, uma vez que as crianças de seis anos da classe média e alta já se

\begin{abstract}
encontram
majoritariamente

incorporadas ao sistema de ensino - na pré-escola ou na primeira série do Ensino Fundamental. A opção pela faixa etária dos 6 aos 14 e não dos 7 aos 15 anos para o Ensino Fundamental de nove anos segue a tendência das famílias e dos sistemas de ensino de inserir progressivamente as crianças de 6 anos na rede escolar. A inclusão, mediante a antecipação do acesso, é uma medida contextualizada nas políticas educacionais focalizadas no Ensino Fundamental. (BRASIL, 2004, p. 16).
\end{abstract}

Acredita-se que a obrigatoriedade do ensino de nove anos possa causar diferença e uma contribuição sólida para a estrutura e cultura da escola. É claro que essa modificação precisa considerar o nível de desenvolvimento dos alunos, ou seja, tem de partir da realidade dos mesmos, seria impossível ampliar o ensino e por a prova os antigos conteúdos da primeira série para o atual primeiro ano (antiga pré-escola).

Sobre essa problemática, o documento do MEC assegura que:

No entanto, não se trata de transferir para as crianças de seis anos os conteúdos e atividades da tradicional primeira série, mas de conceber uma nova estrutura de organização dos conteúdos em um Ensino Fundamental de nove anos, considerando o perfil de seus alunos. (BRASIL, 2004, p. 16).

Em uma análise das pesquisas desenvolvidas junto ao banco de Teses da Capes $^{4}$, desde a aprovação da lei de ampliação do Ensino Fundamental, foi constatado que a preocupação com as implicações curriculares

\footnotetext{
${ }^{4}$ http://www.capes.gov.br/servicos/banco-de-teses
}

\footnotetext{
${ }^{3}$ (IBGE, Censo Demográfico 2000).
} 
desta mudança tem sido feita em grande porcentagem na área de Currículo e Alfabetização. Este dado nos aponta a relevância de desenvolver estudos e reflexões voltados à Educação Matemática nesta modalidade de ensino, podendo revelar aspectos que contribuam para as discussões da área.

Para tal, parto da premissa de que devido a múltiplos fatores, essa a afirmação do Ministério da Educação (MEC) possa não se configurar na prática. Em outras palavras, os professores podem estar ensinando as crianças de seis anos com a proposta antiga de ensino para a $1^{\text {a }}$ série, não respeitando com isso o tempo da infância.

Essa problemática, como bem aponta Goulart (2007) toca em:

Uma questão delicada e importante com que estamos lidando no contexto dessa ampliação do Ensino Fundamental diz respeito à inserção das crianças de seis anos. Crianças que em muitos estados e municípios brasileiros, estavam freqüentando os espaços de Educação Infantil passam a freqüentar a escola de Ensino Fundamental. Que reflexões e revisões precisamos fazer no contexto da escola e de nossas práticas pedagógicas para que essas crianças se sintam abraçadas, acolhidas? (p.79).

Este fato pode contribuir, de forma significativa, para o fracasso escolar e para aumentar os índices insatisfatórios dos sistemas de avaliação do ensino público, comprometendo com isso o desenvolvimento infantil, submetendo nossas crianças a uma escolarização precoce.
Resultados preliminares: conclusões nada conclusivas

A pesquisa encontra-se, quando da escrita deste texto, em sua fase de preparação para retornar ao campo de configuração do estudo, uma vez que o mesmo compreende o período de transição da pré-escola para o $1^{\circ}$ ano do Ensino Fundamental. Desse modo, o que neste texto é apresentado constitui-se em uma parte do levantamento teórico inicial necessário para o desenvolvimento do estudo.

Até o momento, no caso pesquisado, o trabalho com a Matemática na pré-escola tem sido baseado na concepção de que a criança aprende exercitando determinadas noções matemáticas ou ouvindo as informações das professoras. Neste sentido, os dados preliminares revelam que as professoras preocupam-se em transmitir rudimentos numéricos, tais como: reconhecimento de algarismos; nome dos números; domínio de seqüência numérica, bem como os nomes de algumas figuras geométricas, tais como: quadrado, triângulo e o retângulo. A partir destes dados, obtidos por meio das observações em duas salas de pré-escola, considero que seguindo este tipo de prática pedagógica,

[...] na escola infantil o trabalho com a matemática permanece subjacente, escondido sob uma concepção de treinar as crianças a darem respostas corretas, ao invés de fazêlas compreender a natureza das ações matemáticas. [...] Uma proposta de trabalho de matemática para a escola infantil deve encorajar a exploração de uma grande variedade de idéias matemáticas relativas a números, medidas, geometria e noções de rudimentos rudimentares de estatística, de forma que as crianças desenvolvam e conservem um prazer e 
uma curiosidade acerca da matemática.

Nesta perspectiva, como esclarece a autora, uma proposta de trabalho com a disciplina na Educação Infantil, precisa incorporar os contextos do mundo real, as experiências e a linguagem natural da criança no decorrer do desenvolvimento de noções matemáticas, não esquecendo que é papel da escola fazer com que as crianças sigam além do que parecem saber (SMOLE, 2003).

Deixamos claro, também, que não consideramos que a tarefa da escola infantil seja essencialmente preparar a criança para as séries posteriores. Obviamente que, em um projeto pedagógico escolar amplo, é desejável perceber que habilidades e conhecimentos são transferidos de uma série para outra, mas, a nosso ver, isso é mais conseqüência de um trabalho pedagógico consciente, sério e planejado do que causa das ações docentes. A criança entre quatro e sete anos tem interesses e características próprias que devem ser atendidos e contemplados com vistas a esse período de vida e escola, no qual ela se encontra. Não podemos ignorar isso em nome de uma pretensa preparação para séries seguintes. (SMOLE, 2003, p. 63).

Dadas as reflexões acima, trabalhar com a Matemática com crianças em idade de 5 e 6 anos não significa que tenhamos que iniciar os conteúdos de forma sistemática, exigindo resultados concretos, respostas certas, entre outros, porém, não necessariamente ensinar matemática na Educação Infantil significa ser esporádico, espontaneísta e casual. Para termos
"[...] os meios, as mensagens, a forma e o conteúdo, é necessário que as crianças estejam diariamente cercadas por propostas e oportunidades que evoquem o uso da competência lógico-matemática [...]" (IDEM, p. 63), em ligação permanente com a prática do professor, que precisa estar ciente de que a criança de 5 e 6 anos têm especificidades próprias da infância e que a utilização de recursos lúdicos pode potencializar significativamente a aprendizagem matemática, fazendo com que os conteúdos não sejam antecipados, evitando, portanto, uma escolarização precoce.

Cabe acrescentar que uma das vertentes em que a lei que amplia o tempo de duração da escola fundamental é a de exclusão das classes de alfabetização, ainda presentes na Educação Infantil. (BRASIL, 2006).

Existe uma forte relação, nas práticas das professoras investigadas, entre o processo de iniciação à Alfabetização bem como ao ofício de aluno. É evidente, nos casos analisados, a presença de uma centralidade das atividades propostas em sala serem sobre alfabetização, uma vez que segundo as professoras a sala de $1^{\circ}$ ano é muito "cobrada", a criança tem que ser "alfabetizada, não pode seguir sem saber pelo menos os números e as letras, formar palavras, saber escrever o nome". (ENTREVISTA CONCEDIDA $\left.^{5}, 14-12-2010\right)$.

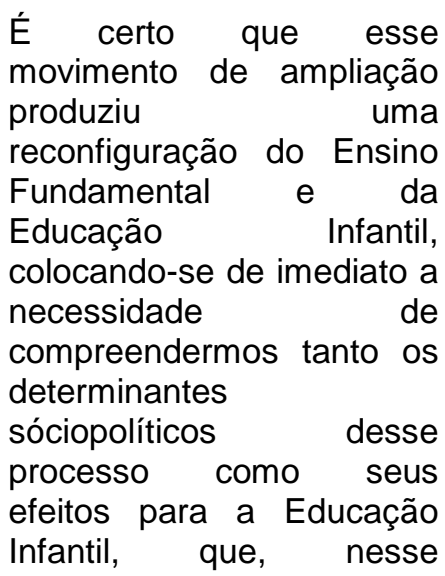

\footnotetext{
${ }^{5}$ Este trecho refere-se a uma entrevista concedida no final do ano de 2010 e que posteriormente foi analisada sob a perspectiva do referencial teórico adotado.
} 
contexto, tem limites legais e pedagógicos em seu âmbito de atuação redefinidos. (SILVA, 2009, p. 28).

Nesta perspectiva, é de relevância averiguar os efeitos dessa mudança curricular para a prática dos professores que ensinam Matemática na Educação Infantil e no $1^{\circ}$ ano da escola fundamental, problematizando no bojo da discussão as implicações para a organização e as práticas pedagógicas na pré-escola, bem como discutir a necessidade de se articular as duas etapas da educação.

Os documentos publicados pelo Ministério da Educação, consultados pelo pesquisador, apontam a melhoria dos índices de alfabetização das crianças como meta central do ensino de nove anos, e assim reforçam tais práticas que valorizam a centralidade nesta área do conhecimento, a partir desses dados considero que investigar como professores que atuam na pré-escola (último segmento da Educação Infantil) e $1^{\circ}$ ano (ingresso do Ensino Fundamental) podem revelar aspectos relevantes no que se refere ao ensino de Matemática neste momento de mudança curricular que estamos vivenciando no contexto educacional brasileiro, na tentativa de encontrar a melhor resposta para uma questão que tem preocupado professores e pesquisadores: Por onde começar? Que Matemática ensinar à criança pequena?

Portanto, as idéias apresentadas neste texto são ainda embrionárias, por se tratar de uma escrita, ainda em processo de construção, o que aqui se apresenta podemos chamar de um ensaio inicial do processo de construção de uma dissertação de mestrado que busca estabelecer um panorama das questões pertinentes ao currículo matemático no período que compreende a transição da Educação Infantil para o Ensino Fundamental e ao mesmo identificar quais as dificuldades encontradas pelas professoras destas turmas para aplicar a nova proposta curricular à sala de aula no que se refere aos conteúdos de Matemática previamente selecionados pela via da prática pedagógica.

\section{REFERÊNCIAS}

ARAÚJO, R. C. B. F. Construindo Sentidos para a Inclusão de Crianças de Seis Anos no Ensino Fundamental: um diálogo com professores. 2008. Dissertação (Mestrado em Educação)- Universidade Federal de Juiz de Fora, Juiz de Fora - MG.

BRANDÃO, C. da F.o.; PASCHOAL, J. D. (orgs.). Ensino Fundamental de Nove Anos: teoria e prática na sala de aula. São Paulo: Avercamp, 2009.

BRASIL. Ministério da Educação. Ensino Fundamental de nove anos: orientações gerais. Ministério da Educação. Secretaria de Educação Básica. Brasília: Ministério da Educação, 2004.

Lei n. 11.114 , de 16 de maio de 2005. Altera os arts. $6^{\circ}, 30,32$ e 87 da Lei $n^{\circ} 9.394$, de 20 de dezembro de 1996, com o objetivo de tornar obrigatório o início do ensino fundamental aos seis anos de idade. Diário Oficial da União, Brasília, DF, 17 maio 2005

Lei n. 11.274, de 6 de fevereiro de 2006. Altera a redação dos arts. 29, 30, 32 e 87 da Lei n. 9.394, de 20 de dezembro de 1996, que estabelece as diretrizes e bases da educação nacional, dispondo sobre a duração de 9 (nove) anos para o ensino fundamental, com matrícula obrigatória a partir dos 6 (seis) anos de idade. Diário Oficial da União, Brasília, DF, 7 fev. 2006.

CALVINO, I. As cidades invisíveis. Tradução: Diogo Mainardi. São Paulo: Companhia das Letras, 1990.

CAMPOS, M. M. O Ensino Fundamental de nove séries e as crianças de seis anos. NUANCES: Estudos sobre Educação. Presidente Prudente, v. 14, n. 15, jan./dez., 2007.

GOULART, C. Ensino fundamental de nove anos: tempo de rever conceitos de infância, de ensino e aprendizagem e de escola. Língua Escrita Belo Horizonte, n.1, jan./abr., 2007.- :

FIORENTINI, D.; LORENZATO, S. Tendências temáticas e metodológicas da pesquisa em Educação Matemática. In: FIORENTINI, D.; LORENZATO, S.. Investigação em Educação Matemática: percursos teóricos e metodológicos. 3. ed. rev. Campinas: Autores Associados, 2009. 
LORENZATO, S. Que Matemática ensinar no

primeiro dos nove anos do Ensino

Fundamental? (2009) Disponível em:

$<$ http://www.alb.com.br/anais17/txtcompletos/sem

07/COLE_2698.pdf>. Acesso em: 04 abr. 2010.

LUDKE, M.; ANDRÉ, M. E. D. A. Pesquisa em Educação: Abordagens Qualitativas. São Paulo: E.P.U, 1995.

MOYA, D..J. L. A Criança de Seis Anos de Idade no Ensino Fundamental: práticas e perspectivas. 2009. Dissertação (Mestrado em Educação), Universidade Estadual de Maringá (UEM), Maringá - PR.

SMOLE, K. C. S. A Matemática na Educação Infantil: a teoria das inteligências múltiplas na prática escolar. Porto Alegre: Artmed, 2003.

SILVA, R.. A implementação do Ensino Fundamental de nove anos e seus efeitos para a Educação Infantil: um estudo em municípios catarinenses. 2009. Dissertação (Mestrado em Educação) - Programa de Pós-graduação em Educação. Centro de Ciências da Educação. Universidade Federal de Santa Catarina. 